\title{
The Dynamics of Training Outcomes in a Training Experience
}

\section{Chong Siaw Fung ${ }^{1}$ \\ Peter Songan ${ }^{2 *}$}

1.2 Universiti Malaysia Sarawak, 94300 Kota Samarahan, Sarawak, Malaysia

\begin{abstract}
It is rather common to find researchers and practitioners in training and development evaluating training effectiveness based on Kirkpatrick's criteria of training reactions, learning, behavior change, and overall results. In recent years, in-depth review of Kirkpatrick's criteria for training evaluation by theorists and researchers resulted in renewed interest in possible underlying dimensions and more operationalized measures of these factors. In this study, a hypothesized model is proposed to explain the effects of training reactions on learning outcomes and training transfer. Path analysis is carried out on data collected from 118 participants of a training course on operational housekeeping to examine the validity of the proposed model. Training reactions is considered in terms of affective reactions and utility reactions, and learning is considered in terms of declarative learning and application-based learning. Moderate effects between affective reactions, declarative learning, and training transfer are observed; while the links between affective reactions and utility reactions, and between declarative learning and application-based learning appeared to be more significant.
\end{abstract}

Keywords: training evaluation; training reactions; learning outcomes; training transfer; training effectiveness

\section{INTRODUCTION}

Research efforts in relations to training evaluation often make references to Kirkpatrick's $(1967,1987,1994)$ criteria of training out-

\section{ARTICLE INFO}

E-mail address:

songan@unimas.my (Peter Songan)

*Corresponding author

ISSN: 2462-1153

(C) Faculty of Cognitive Sciences and Human Development, Universiti Malaysia Sarawak (UNIMAS) comes. For the purpose of training evaluation, Kirkpatrick proposed four criteria:

i. Reactions: trainee's "liking of" and "feelings for" a training program;

ii. Learning: principles, facts, and techniques understood and "absorbed" by trainees;

iii. Behavior: the application of learned principles and techniques on the job, resulting in a change in job behavior; and 
iv. Results: overall performance improvement demonstrated by trainees, contributing to organizational results.

Over the years, implicit assumptions seemed to have been formed about the relationship between these criteria, and studies had been conducted based on such assumptions (Alliger \& Janak, 1989). For instance, it was assumed that the criteria are hierarchical levels of training outcomes, such that the levels are causally linked from one to another, and that they are all positively correlated with one another. Thus, the notion that reactions affect learning, learning affects behavior, and behavior affects results is generally acceptable in considering the four criteria proposed by Kirkpatrick (1967, 1987, 1994). Due to the structure of relationship thus assumed, some refer to Kirkpatrick's model as the hierarchical model of training evaluation (Noe, 1986; Noe \& Schmitt, 1986).

\section{Revisiting Kirkpatrick's Criteria of Training Effectiveness}

Alliger and Janak (1989) reviewed some 203 articles on training evaluation to examine correlation between Kirkpatrick's levels of training evaluation criteria. They found that correlations between the three upper levels appears to be slightly larger, casting doubt on the assumption that reactions would affect learning, behavior, and results. Their findings challenged the general hierarchical assumptions of the relationship between Kirkpatrick's criteria of training effectiveness.

Another effort of reviewing literature was carried out based on revised ideas related to Kirkpatrick's model (Alliger et al. 1997). By then, it was observed that researchers using Kirkpatrick's model for training evaluation have contributed to the model over the years. Based on ideas collected from the review of these studies, an updated version of Kirkpatrick's levels of training criteria were presented with added sub-levels (Alliger et al. 1997) as describe, below:

\section{Reactions:}

i. Affective reactions: liking of and feelings for the training experience.

ii. Utility reactions: perceived relevance, utility value, or usefulness of training for subsequent job performance.

iii. Combined reactions: combining both affective and utility components of reactions - applied in some researches where no effort is made to distinguish the two components.

\section{Learning:}

i. Immediate post-training knowledge: level of knowledge acquired immediately after training experience.

ii. Knowledge retention: level of knowledge assessed at a later time rather than immediately after training.

iii. Behavior/Skill demonstration: behavior/skill test administered at the conclusion of training.

3. Transfer: this is regarded as "...on-thejob performance..., ...taken some time after training, ....some measurable aspect of job performance" (Alliger et al, 1997, p.346). In certain respect, this is synonymous to what was "behavior" in the original model.

4. Results: organizational impact of the training, e.g., productivity gains, customer satisfaction, cost-savings, employee morale, etc.

In the meta-analysis of 34 studies and 115 correlations between levels of training criteria, Alliger et al. (1997) observed positive correlations were between affective and utility reactions, and between immediate and delayed learning measures. A slight correlation between reactions and immediate learning was found, not sufficient to conclude that reactions can be used to surrogate for assessment of learning. 
Some expressed doubts about Kirkpatrick's model for training evaluation. Kraiger, Ford, and Salas (1993) criticized Kirkpatrick's model for its lack of clarity regarding what specific changes may be expected as a function of trainee learning; and its difficulty in identifying what assessment techniques are appropriate. They proposed a Classification Scheme of Learning Outcomes, covering three levels of learning outcomes - cognitive, skill-based, and affective - and the sublevels.

Holton (1996), while criticizing the effectiveness of Kirkpatrick's model proposed a HRD Evaluation and Research Model which considered three primary components of outcomes from training, namely, learning, individual performance (training transfer), and organizational results; and considered reactions only as an intervening variable for learning and transfer. He also proposed that the components of outcomes mentioned would be influenced by motivation, environmental, and enabling elements; where some secondary influences would affect the motivational elements.

Gist and Stevens (1998) in their attempt to operationalize measures of learning outcomes in a negotiation skills training proposed a two-level approach to measuring learning outcomes:

\section{Cognitive levels}

i. Recall: committing training contents to retention and short-term memory.

ii. Comprehension: generalization of learned knowledge to similar context.

iii. Synthesis: cognitive connection between declarative knowledge and other stimuli to produce advance knowledge compilation.

\section{Behavioral levels}

i. Practice: behavioral demonstration of appropriate knowledge in simulated context.

ii. Performance: behavioral demonstra- tion of appropriate knowledge in natural setting.

The efforts of researchers, such as, Alliger et al. (1997), Kraiger, Ford, and Salas (1993), Holton (1996), and Gist and Stevens (1998) raised questions about the hierarchical relationship model of Kirkpatrick's criteria of training effectiveness, and also demonstrated an understanding that measures of training reactions and learning should be more specific than the original Kirkpatrick's definitions. Incidentally, efforts of specialized operationalization of these measures have already been demonstrated in more recent studies (Gist \& Stevens, 1998; Tracey, Hinkin, Tannenbaum, \& Mathieul, 2001).

\section{The Dynamics of Training Outcomes}

The controversy revolving the interrelationship between Kirkpatrick's criteria of training effectiveness raised questions related to the dynamics between these training outcome measures, such as:

i. How are training reactions, learning, and transfer related to one another?

ii. How do the "sub-levels" or components within each of these criteria, especially training reactions and learning affect one another?

The effect of training reactions on learning and training transfer is quite commonly acknowledged. Supposedly, trainees having positive disposition towards a training experience are likely to be more motivated to learn and subsequently apply what is learned in their work. This proposition is somewhat illustrated in the proposed model of Noe (1986). Although the attempt to test the model met with disappointing results (Noe \& Schmitt, 1986), the notion that training reactions may contribute to learning, and subsequently training transfer is worthy of consideration. In another model proposed by Elangovan and 
Karakowsky (1999), trainees who perceived the training contents and experience to be relevant to their job are more likely to initiate transfer of learned knowledge and skills in their work environment.

Trainees' attitudinal factors may affect learning and transfer. Measuring learning in terms of cognitive knowledgegain and post-training behavioral performance, and training transfer in terms of skill maintenance seven weeks after a training program on negotiation skills, Gist, Stevens, and Bavetta (1991) found significant evidence of the effect of trainees' self-efficacy on their learning and ability to transfer, indicating possible links between trainees' reactions, learning and transfer.

Training approaches may affect training reactions, learning, and training transfer. Gist, Bavetta, and Stevens (1990) found that different training intervention, such as, self-management and goal-setting produced various degree of training transfer. Specific skills or features adopted in training experience with the objective to enhance training transfer were found to be quite effective in producing better behavior performance during training (Gopher, Weil, \& Bracelet, 1994), but insignificant in promoting transfer (Gopher et al..1994; Lintern, Shepard, Parker, Yates, \& Nolan, 1989). Perhaps, the different training methodologies induced different feelings among the trainees, giving rise to different levels of learning and transfer.

One study demonstrated significant effects between various sub-levels of training reactions and learning. Tracey et al. (2001) observed significant links between affective reactions, utility reactions, declarative learning, and application-based learning. They confirmed their hypothesized model and found that affective reactions had significant effects on utility reactions, and likewise, learning of declarative knowledge on learning of application-based knowledge. They also found that utility reactions had moderately significant effects on learning of declarative knowledge.

\section{OBJECTIVES OF THE STUDY}

Specifically, the objectives of this study are:

i. To determine training reactions, learning outcomes and training transfer among a group of trainees participating in a training program on operational housekeeping practices.

ii. To determine the effect of training reactions on learning outcomes among a group of trainees participating in a training program on operational housekeeping practices.

iii. To determine the effect of training reactions and learning outcomes on training transfer among a group of trainees participating in a training program on operational housekeeping practices.

\section{Hypothesized Model}

Based on the review of literature, a hypothesized model for this study was formulated, as illustrated in Figure 1. Training reactions are considered to have effect on declarative and application-based learning, and also training transfer (Gist et al., 1991; Noe, 1986; Tracey et al., 2001). Meanwhile, learning is also expected to contribute to transfer (Gist et al. 1991). Trainees' feelings toward the training are expected to affect their utility reactions, and declarative learning is expected to affect application-based learning as observed by Tracey et al.(2001).

\section{OPERATIONAL DEFINITIONS}

Following the suggestions of Alliger et al. (1997), Gist and Stevens (1998), and Kraiger et al. (1993), measures of training reactions and learning are operationalized, below. 
Chong Siaw Fung and Peter Songan

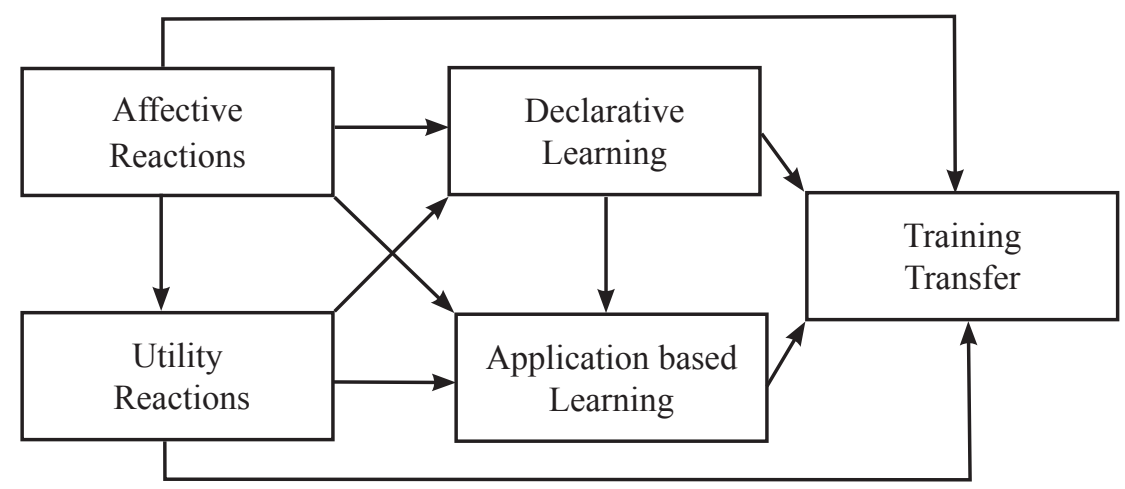

Figure 1: Hypothesized model of the study

Training reactions are measured in terms of the following:

i. Affective reactions: trainees' attitudes - liking and feeling toward the training experience in the training program.

ii. Utility reactions: the extent to which the trainees consider the contents and activities in the training program as relevant or useful in their daily work.

Trainees' learning is measured using pre-training and post-training written test, covering the following:

i. Declarative learning: gain in theoretical and cognitive knowledge about the subject matter presented in the training program.

ii. Application-based learning: gain in skill-based knowledge, reflected by trainees' ability to describe how he or she would deal with a given work situation.

Training transfer is considered as observed work behavior change three months after going through the training program.

\section{METHODOLOGY}

The methodology utilized in this study is a simple quasi-experimentation in the form of the one-group pretest-posttest design, a design which is commonly used in the social sciences (Cook \& Campbell, 1979). This design was selected to enable pretest observations to be made on the trainees before they attend the training, who later will receive a treatment (the training), after which a posttest observations are made.

The subjects of this study were 118 operational personnel in nine manufacturing organizations around Sabah and Labuan Federal Territory in Malaysia. This included 90 males and 28 females of various ethnic backgrounds: Malays (25.6\%), Kadazan and Dusuns (26.5\%), Bajaus and other Bumiputeras (30.8\%), Chinese (11.1\%), and others (6.0\%). Most of them worked in factory operations and maintenance $(77.1 \%)$, others in administrative and clerical functions (14.4\%), and keeping of warehouses or storage places $(8.5 \%)$. In terms of educational attainment, the largest group of subjects had completed upper secondary education (57.3\%); $19.6 \%$ of them had either completed lower secondary or primary education; and the remaining $23.1 \%$ of them had either completed pre-university education or higher.

The subjects of the study were selected by their organizations to participate in a 1-day training program on operational housekeeping practices. This training program was developed especially for the purpose of this study, and was conducted by an experienced trainer in batches of 15 to 30 trainees over a period of one year. Training intervention approaches used 
Chong Siaw Fung and Peter Songan

Table 1: Declarative learning, application-based learning, and training transfer

\begin{tabular}{|l|c|r|r|r|r|}
\hline & $\begin{array}{c}\text { Total } \\
\text { Scores }\end{array}$ & \multicolumn{1}{c|}{$\begin{array}{c}\text { Pre-training } \\
\text { Mean }\end{array}$} & \multicolumn{1}{c|}{$\begin{array}{c}\text { Post- } \\
\text { training } \\
\text { Mean }\end{array}$} & \multicolumn{1}{c|}{$\boldsymbol{t}$} & $\boldsymbol{p}$ \\
\hline Declarative Learning & 15 & 3.67 & 6.41 & -13.605 & .000 \\
Application-based Learning & 25 & 16.14 & 24.63 & -20.834 & .000 \\
Training Transfer (T1-T2) & - & 49.49 & 51.47 & -7.930 & .000 \\
\hline
\end{tabular}

were predominantly lectures supported by visual aids, that is, Powerpoint slides projected through an LCD projector. After going through the course contents, each batch of trainees were organized into action-planning groups, in which they discussed about how they would apply the principles learned at their workplace.

Pretest and posttest were administered before and after the training program to measure declarative and applicationbased learning. These were parallel tests developed based on the contents of the training program. Each test contained 25 questions in two sections testing trainees' knowledge on the training contents. Section A had 15 multiple-choice items testing trainees' cognitive knowledge about the subject matter, and Section B contained 10 items testing trainees' ability to apply learned knowledge in given situations.

An instrument entitled Training Reactions Survey (TRS) was developed to measure trainees' affective and utility reactions in the training course. It consisted of eight 7-point Likert scaled items: four items to measure affective reactions and another four items to measure utility reactions. These items had been pilot tested and the scales of four items each for trainees' affective reactions and utility reactions yielded Cronbach's alpha values of 0.8729 and 0.8264 , respectively. TRS was administered immediately after conducting posttest in the training program.

Behavioral observation was conducted at the trainees' work sites to as- sess their work behavior related to the principles of operational housekeeping practices covered in the training program. The observation was guided by a checklist containing 20 behaviorally anchored items to assess specific work behavior in three specific areas of housekeeping practices: organization, orderliness, and cleanliness. Trainees' behaviors were observed through visible indications of such practices at work. Behavioral observation was first conducted one week before the training program (T1) to obtain the baseline work behavior before the training experience. Three months after the training program (T2), another behavioral observation was conducted to assess post-training behavior. The extent of training transfer was considered on the basis of the differences in work behavior scores recorded during observation done one week before (T1) and three months after the training program (T2).

The data collected from 118 trainees in a 1-day operational housekeeping training program were analyzed by conducting a path analysis to verify the hypothesized model.

\section{FINDINGS AND DISCUSSION}

The findings of this study are presented and discussed, below.

\section{Training Outcomes}

In terms of training reactions, the trainees were generally positive towards the train- 
Chong Siaw Fung and Peter Songan

Table 2: Path analysis based on hypothesized model

\begin{tabular}{|c|c|c|c|c|}
\hline Dependent Variable & $\begin{array}{c}\text { Independent } \\
\text { Variables }\end{array}$ & $\begin{array}{c}\text { Standardized } \\
\text { Beta }\end{array}$ & $t$ & $p$ \\
\hline Utility Reactions & Affective Reactions & .522 & 6.587 & $.000^{\mathrm{a}}$ \\
\hline \multirow[t]{2}{*}{ Declarative Learning } & Affective Reactions & .174 & 1.611 & $.110^{\mathrm{d}}$ \\
\hline & Utility Reactions & -.075 & -.692 & .491 \\
\hline Application-based & Affective Reactions & -.126 & -1.168 & .245 \\
\hline \multirow[t]{2}{*}{ Learning } & Utility Reactions & .007 & .070 & .945 \\
\hline & Declarative Learning & .211 & 2.284 & $.024^{\mathrm{b}}$ \\
\hline \multirow[t]{4}{*}{ Training Transfer } & Affective Reactions & -.062 & -.551 & .583 \\
\hline & Utility Reactions & .011 & .102 & .919 \\
\hline & Declarative Learning & .172 & 1.774 & $.079^{\mathrm{c}}$ \\
\hline & $\begin{array}{l}\text { Application-based } \\
\text { Learning }\end{array}$ & .019 & .196 & .845 \\
\hline
\end{tabular}

ing experience. On a 7-point scale in the TRS, the mean scores registered for affective and utility reactions are 6.098 and 6.025, respectively. Significant evidence of declarative and application-based learning was also observed (Table 1). Training transfer measures based on work behavior observation at period T1 and T2 had also been found to be significantly different (Table 1). Based on these findings, the trainees were generally positive towards the training experience, and the training program appeared to have effectively in- duced learning and transfer.

\section{Path Analysis}

Statistically, a multiple regression analysis was conducted to verify each path illustrated in the hypothesized model. Variables hypothesized to be contributing to certain dependent variable were entered as independent variables simultaneously to observe the significance of the standardized Beta coefficient for the linear relationship. In doing this, the significance of

$-0.62$

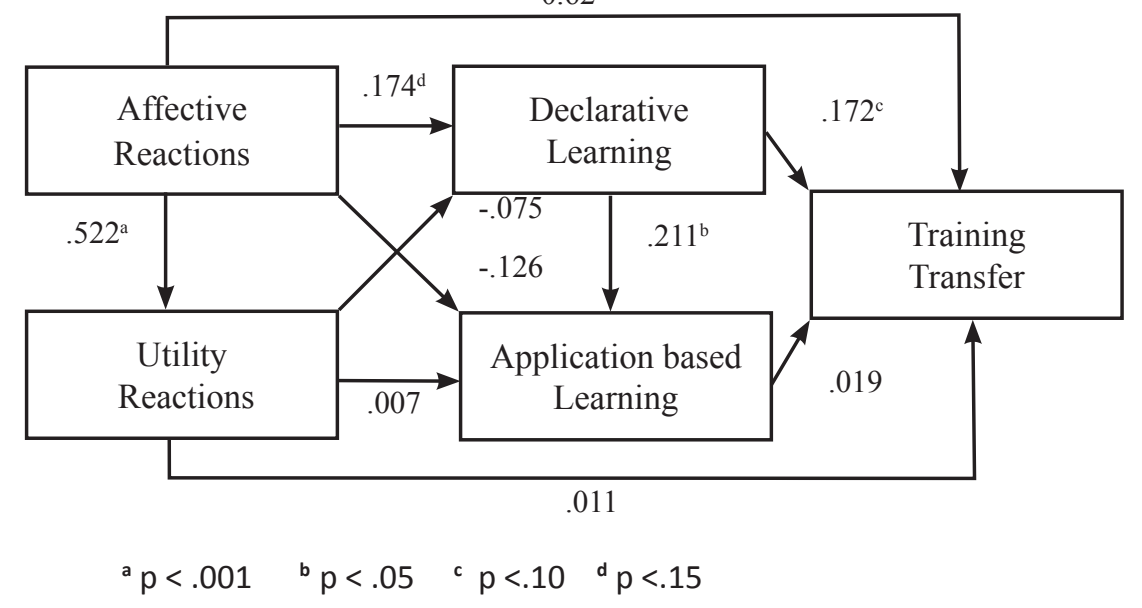

Figure 2: Hypothesized model with path coefficients 
the independent variables as predictors of the dependent variable was assessed. The results of this statistical analysis are displayed in Table 2. The hypothesized model after entering the standardized Beta coefficients into their respective paths is shown in Figure 2.

The analysis confirmed moderate to strong effects of certain measures of training reactions towards learning and training transfer. Affective reactions were found to have strong significant impact on utility reactions $(B=.522 ; t=6.587$, $p<.001)$, and slight effect on declarative learning $(B=.174 ; t=1.611, p<.15)$. Declarative learning appeared to have significant effect on application-based learning $(\mathrm{B}=.211 ; t=2.284, p<.05)$, and moderate effect on training transfer $(B=.172 ; t$ $=1.774, p<.10)$. There is insignificant evidence to support the other paths in the hypothesized model.

There seem to be a general acceptance of Kirkpatrick's (1967, 1987, 1994) criteria of training effectiveness as the basis for training evaluation. Some researchers questioned the validity of this model and the implicit assumptions made about the interrelationship between the criteria (Alliger \& Janak, 1989; Alliger et al, 1997; Kraiger et al, 1993, Holton, 1996, Gist \& Stevens, 1998). In this study, a hypothesized model was formulated to describe the dynamics between training reactions, learning, and training transfer.

\section{Evaluation of Training Effectiveness}

In general, the trainees indicated rather positive reactions to the training experience, sustaining high scores for affective reactions and utility reactions. The trainees apparently felt good about the training experience, and perceived it to be useful for their work. The level of trainees' learning - declarative and application-based was found to be significant by comparing the pretest and posttest scores. Also, significant changes of trainees' work behav- iors related to operational housekeeping three months after the training program (T2) are observed compared to their work behaviors one week before the training program (T1). All these findings apparently confirmed that the trainees were positive about the training, learned something from it, and subsequently applied some learned knowledge and skills at work. Hence, the training program can be considered effective according to these criteria proposed by Kirkpatrick (1967, 1987, 1994).

\section{Revised Model}

A multiple regression analysis was conducted to verify the hypothesized model. The standardized Beta coefficients for the paths in the hypothesized model were determined to test their statistical significance. This process yielded evidence to support the significance of the effects between affective reactions, declarative learning, and training transfer. Meanwhile, ffective reactions appeared to have significant effect on utility reactions, and declarative learning on application-based learning. The dynamics of these measures are illustrated in Figure 3.

\section{Reactions and Learning}

The findings of this study supported the links between affective reactions and utility reactions, and between declarative learning and application-based learning. Both these links had been confirmed by Tracey et al. (2001). Trainees' attitudes towards a training experience (affective reactions) would apparently affect their feelings and perception of whether the knowledge and skills learned would be useful to them at work (utility reactions). Reactions appeared to be influenced by participants' insightful thoughts and perception of support from their supervisors. This is consistent with Holton's (1996) argument about reactions not being a direct outcome of training. Trainees' feelings about training 


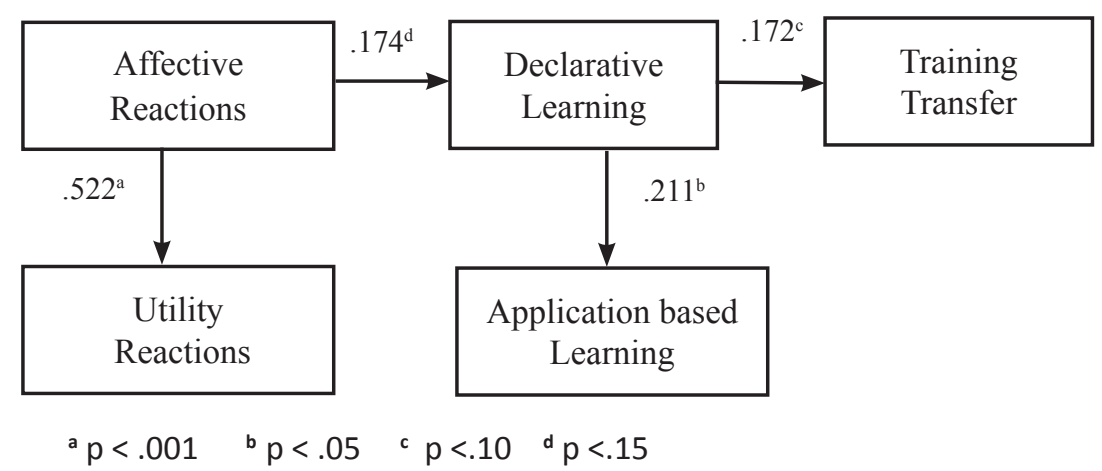

Figure 3: Revised model with path coefficients

experience might be a product between the training design conditions and their perception of themselves, their superiors, and their organizations as they go through a training experience.

Similarly, the gain of cognitive knowledge from a training program (declarative learning) would enhance the trainees' ability to generalize the related skills in given situations (applicationbased learning). Cognitive behaviors have strong influence over learning in declarative knowledge. This finding is supported by Holton (1996), who proposed that personality characteristics and intervention readiness would affect motivation to learn, which further clarified to be performance self-efficacy and learner readiness.

\section{Training Transfer}

The revised model portrayed a sequential path where trainees' affective reactions to training affected their declarative learning, and declarative learning affected the eventual training transfer measure. Although Tracey et al. (2001) had observed significant effect between utility reactions and declarative learning, insufficient evidence is found in this study to support such notion. Instead, trainees' affective reactions had been found to have slight impact on their declarative learning. Trainees' de- clarative learning had been observed to moderately affect their work behaviors three months after the training. This suggests that trainees' feelings about a training experience (affective reactions) would affect their gain in declarative knowledge (declarative learning) in the training program. Following that, the extent of declarative learning sustained by the trainees would contribute to their ability to apply the learned knowledge and skills in their daily work situations (training transfer).

According to the statistical evidence in this study, the causal links between affective reactions and utility reactions, and between declarative learning and application-based learning appeared to be more significant compared to the links between affective reactions, declarative learning, and training transfer. Meanwhile, the significance of the other paths proposed in the hypothesized model cannot be proven.

This finding seemed to agree with the argument of some researchers, who disputed the general hierarchical assumption of Kirkpatrick's criteria of training effectiveness, and contended that empirical evidence of correlation between training reactions and the other criteria, especially learning is somewhat inconclusive (Alliger \& Janak, 1989; Alliger et al, 1997). Perhaps the relationship between trainees' 
reactions, learning outcomes, and ability to transfer is mediated by some extraneous factors, such as, trainees' self-efficacy and training intervention approaches (Gist et al. 1990; Gist et al. 1991; Gopher et al. 1994; Lintern et al. 1989). However, the training methodology employed in this study is controlled for all trainees in this study. Thus, the effect between training reactions and learning found in this study is more likely to have been moderated by factors other than training intervention approaches.

It was rather interesting to find that, apart from declarative learning, there are no other factors having significant impact on training transfer. Although application-based learning may be more likely to have direct influence on training transfer than declarative learning, the results of this study revealed otherwise. Trainees' gain in cognitive knowledge about the subject matter learned in the training experience seemed to have more influence on their ability to transfer the learned knowledge and skills to actual work situations.

Analysis of the test scores for the application-based knowledge items revealed quite high mean pretest scores (16.14 out of 25). Trainees are quite capable of indicating the desirable work behaviors under given situations even before the training program. Due to the high entry scores for application-based knowledge, there may have been a tendency for the posttest scores to regress towards the mean. If so, the statistical significance of the effect of application-based learning on training transfer may be limited; and declarative learning may end up projecting itself more significant as a predictor of training transfer, as is found in this study. It is also possible that the trainees indicated desirable work behaviors for the application-based items in the pretest as social responses, rather than based on sound knowledge and understanding.

\section{CONCLUSION AND RECOMMEN- DATIONS}

The results of this study confirmed the significance of several paths in a hypothesized model. It was observed that trainees' affective reactions would affect their utility reactions $(B=.522 ; t=6.587, p<.001)$, and that their declarative learning would affect application-based learning $(B=.211$; $t=2.284, p<.05)$. It appears that trainees having positive feelings towards a training experience are more likely to perceive the training as useful and relevant. Trainees who had acquired declarative knowledge through the training experience would be more able to generalize and apply the concepts learned to actual work situations.

Affective reactions is found to have slight effect on declarative learning $(B=.174 ; t=1.611, p<.15)$, and declarative learning moderately affect training transfer $(B=.172 ; t=1.774, p<.10)$. Apparently, trainees who feel good about a training experience may be more likely to learn cognitive details. Perhaps when trainees are positive about a training experience, they would be more diligent in their efforts to acquire new knowledge and skills from it. Also, the results of this study indicated that trainees who succeeded to acquire declarative knowledge are better able to demonstrate changed work behaviors at work after the training. Apparently, significant learning of new knowledge may improve the possibility of trainees applying acquired knowledge and skills at work.

It seemed that trainees' affective reactions contribute quite significantly towards learning and subsequently training transfer. Meanwhile, utility reactions may also be an effective contributing factor (Tracey et al. 2001), although there is insufficient evidence to support this notion in this study. Thus, instructional developers and trainers should make efforts to create enjoyable and meaningful training experience for trainees to induce positive feelings towards it. Training contents and ac- 
tivities should be carefully selected and designed to help trainees see their relevance and usefulness at work. Also, supervisors should provide support to the trainees in terms of encouragement and opportunities to go for training. Improved training reactions among trainees would positively affect learning and subsequently training transfer.

Declarative learning would significantly enhance trainees' ability to apply the knowledge and principles in given work situations (application-based learning), and moderately affect trainees' ability to put the learned knowledge into practice at work (training transfer). This seemed to suggest that ability to indicate desirable work behaviors in given situations does not necessarily affect change in work behaviors. Rather, sound understanding and retention of knowledge and principles from a training experience may contribute more effectively towards training transfer. Therefore, trainers should work hard to help trainees learn up declarative knowledge in a training experience. The extent of training transfer will be improved following the trainees' learning of declarative knowledge.

The direction of the causal relationships of the paths examined in this study is another point of interest. Since training transfer is measured three months after the training program (T2), the conclusion that declarative learning would affect training transfer in this study can be considered reasonable. However, training reactions and learning measures are taken before and after the training program, registering trainees' attitudes about the training experience and their knowledge-gain. Thus, these variables may not be mutually exclusive and might be interrelated with one another. Although it is established based on a hypothesized model in this study that affective reactions affect utility reactions, and that declarative learning affect application-based learning, the causal relationship might be significant in the reverse direction, as well. In order to ascertain the causal relationships between these variables, further research should be conducted to determine whether affective reactions cause utility reactions or the reverse or both ways; and declarative learning cause application-based learning or the reverse or both ways.

\section{REFERENCES}

Alliger, G. M. \& Janak, E. A. (1989). Kirkpatrick's levels of training criteria: Thirty years later. Personnel Psychology, 42(2), 331-342.

Alliger, G. M., Tannenbaum, S. I., Bennett, W. Jr., Traver, H., \& Shotland, A. (1997). A meta-analysis of the relations among training criteria. Personnel Psychology, 50(2), 341358.

Cook, T. D., \& Campbell, D. T. (1979). Quasi-experimentation: Design \& analysis issues for field settings. Boston, MA: Houghton Mifflin Company.

Elangovan, A. R. \& Karakowsky, L. (1999). The role of trainee and environmental factors in transfer of training: An exploratory framework. Leadership and Organization Development Journal, 20(5), 268-276.

Gist, M. E. \& Stevens, C. K. (1998). Effects of practice conditions and supplementary training method on cognitive learning and interpersonal skill generation. Organizational Behavior and Human Decision Processes, 75(2), 142-169.

Gist, M. E., Bavetta, A. G., \& Stevens, C. K. (1990). Transfer training method: Its influence on skill generalization, skill repetition, and performance level. Personnel Psychology, 43, 501-523.

Gist, M.E., Stevens, C. K., \& Bavetta, A. G. (1991). Effects on self-efficacy and posttraining intervention on the 
acquisition and maintenance of complex interpersonal skills. Personnel Psychology, 44, 837-861.

Gopher, D., Weil, M., \& Bareket, T. (1994). Transfer of skill from a computer game trainer to flight. Human Factors, 36, 387-405.

Holton, E. F. III. (1996). The flawed fourlevel evaluation model. Human Resource Development Quarterly, 7(1), 5-21.

Kirkpatrick, D. L. (1967). Evaluation. In R. L. Craig and L. R. Bittel (Eds.), Training and development handbook (87-112). New York: McGraw-Hill.

Kirkpatrick, D. L. (1987). Evaluation. In R. L. Craig (Ed.) Training and development handbook ( $3^{\text {rd }}$ ed.) (301319). New York: McGraw-Hill.

Kirkpatrick, D. L. (1994). Evaluating training programs: The four levels. San Francisco, CA: BerrettKoehler Publishers.

Kraiger, K., Ford, J. K., \& Salas, E. (1993). Application of cognitive, skill-based, and affective theories of learning outcomes to new methods of training evaluation. Journal of Applied Psychology, 78(2), 311-328.

Lintern, G., Sheppard, D. J., Parker, D. L., Yates, K. E., \& Nolan, M. D. (1989). Simulator design and instructional features for air-toground attack: A transfer study. Human Factors, 31(1), 87-99.

Noe, R. A. (1986). Trainees' attributes and attitudes: Neglected influences on training effectiveness. Academy of Management Review, 11(4), 736-749.

Noe, R. A. \& Schmitt, N. (1986). The influence of trainee attitudes on training effectiveness: Test of a model. Personnel Psychology, 39(3), 497523.

Tracey, J. B., Hinkin, T. R., Tannenbaum, S. I., \& Mathieu, J. E. (2001). The influence of individual characteristics and the work environment on varying levels of training outcomes. Human Resource Development Quarterly, 12(1), 5-23. 